\title{
Educação não escolar em contexto de trabalho: indícios para a educação de jovens e adultos
}

Leonardo Luiz de Souza Matos*

Luis Felipe Soares Serrao**

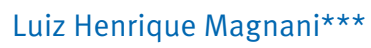

Márcia Rodrigues de Souza Mendonça****

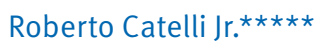

*Ação Educativa (São Paulo, SP, Brasil)

**Ação Educativa (São Paulo, $\mathrm{SP}$, Brasil)

$\star \star \star$ Universidade Federal dos Vales do Jequitinhonha e Mucuri (Diamantina, MG, Brasil)

$\star \star \star \star$ Universidade Estadual de Campinas (Campinas, SP, Brasil)

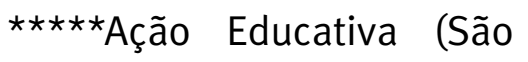
Paulo, SP, Brasil)
Resumo: Este artigo busca aprofundar as discussões sobre usos da linguagem em contexto de trabalho para elucidar aspectos importantes no processo de concepção e de execução de propostas educacionais para jovens e adultos trabalhadores. Para tanto, apresenta os principais resultados de uma experiência de educação não escolar em uma indústria petroquímica, elaborada com foco no desenvolvimento de práticas de letramento e de numeramento situadas de acordo com o contexto de vida e de trabalho dos sujeitos envolvidos. Em linhas gerais, este artigo aponta que jovens e adultos trabalhadores possuem vivências e trajetórias de vida que favorecem(eram) o domínio de práticas de letramento e de numeramento próprias a determinadas realidades e que não necessariamente são práticas intercambiáveis, ou seja, aponta a necessidade de aproximação entre propostas formativas e 0 cotidiano dos sujeitos a que se dirigem.

Palavras-chave: Educação não escolar. Educação de jovens e adultos. Letramentos. Numeramentos. Alfabetismo. 


\section{APRESENTAÇÃO}

Este artigo apresenta e discute aspectos sobre a relação entre a educação e sua inserção no mundo do trabalho. Para tanto, partiu de uma experiência de educação não escolar de jovens e adultos trabalhadores, desenvolvida pela Ação Educativa e Diretoria Regional do Estado da Bahia do Serviço Social da Indústria (Sesi) ao longo de 2013 e 2014. A proposta educativa da instituição era constituir um curso para jovens e adultos que pudesse levar os trabalhadores a um maior domínio de um conjunto de práticas de letramento e numeramento relacionadas às suas tarefas cotidianas da vida e do trabalho. Os cursistas seriam avaliados na entrada e na saída do curso por meio de instrumentos escritos, com base em uma matriz de avaliação especialmente construída para os contextos de trabalho, centrada em habilidades e competências de linguagem e de matemática específicas (cf. AÇÃO EDUCATIVA; SESI, 2014a).

A base da proposta partiu de uma metodologia desenvolvida por especialistas nas áreas de linguística aplicada, matemática e educação de jovens e adultos. Parte do processo consistia na realização de uma experiência piloto, a qual contou com um material didático específico, que abordava, de modo integrado, questões das áreas citadas vinculadas ao contexto social e profissional dos cursistas: trabalhadores da indústria petroquímica na cidade de Camaçari (BA). 0 desenvolvimento desse material ficou sob a responsabilidade de outra parte da equipe, interligada à primeira. A esse segundo grupo de especialistas também foi atribuída a tarefa de formar mediadores para a execução do curso diretamente junto aos trabalhadores. Além de discutir previamente com os mediadores tanto a metodologia quanto o material proposto e deixar em aberto a possibilidade de constante diálogo a respeito do que ocorria durante o curso, toda essa equipe pôde acompanhar, in loco e a distância, os encontros da experiência piloto de curso.

As informações aqui apresentadas foram coletadas ao longo dessa experiência piloto realizada em 2014, a partir de documentos e registros criados, principalmente, no período de elaboração e realização do projeto. Dentre esses, destacam-se: fichas avaliativas do curso respondidas pelos cursistas; fichas de avaliação por módulo respondidas pelos mediadores; produções escritas dos cursistas, mediante autorização deles e dos mediadores; questionário padronizado com perguntas fechadas e abertas para aqueles trabalhadores que se inscreveram, mas nunca frequentaram o curso (chamados de egressos); relatórios de observação in loco do 
andamento dos encontros das turmas; rodas de conversa com concluintes dos cursos, realizadas a partir de um roteiro de perguntas semiestruturadas; entrevistas semiestruturadas com mediadores; e, por fim, por relatos escritos por mediadores sobre a experiência.

\section{INTRODUÇÃO}

Sobretudo nas últimas décadas, governo, empresas, sindicatos, instituições religiosas, movimentos e organizações sociais vêm se dedicando à educação do trabalhador, ora seguindo uma linha de formação de recursos humanos, respondendo a expectativas e demandas dos setores produtivos (empregadores), ora aliando-se a processos de formação e emancipação política da classe trabalhadora. Enquanto movimentos sociais e organizações sindicais estiveram diretamente envolvidos com essa segunda linha, o Estado brasileiro focou seus esforços na linha de aperfeiçoamento e capacitação do trabalhador para o mercado de trabalho.

Desde pelo menos a década de 1990, estratégias governamentais como, por exemplo, o Plano Nacional de Qualificação do Trabalhador (Planfor), o Programa Nacional de Integração da Educação Profissional ao Ensino Médio na Modalidade de Educação de Jovens e Adultos (Proeja) e o Programa Nacional de Acesso ao Ensino Técnico e Emprego (Pronatec), simbolizam as ações no campo da educação para fortalecimento da competitividade econômica brasileira e, cada um a sua maneira, reforçam a lógica de investimento em produção e disseminação de conhecimento e informação como vetor estratégico de desenvolvimento econômico e social do país. E esse não é um cenário unicamente brasileiro.

Movimento similar já ocorria em países europeus nas décadas de 1980 e 1990, nos quais, como indica Di Pierro (1998), ganhava corpo a concepção de sociedade informacional fortemente assentada em releituras da teoria do capital humano. A partir de tais concepções, passaram a ter importância estratégica a produção e a disseminação do conhecimento nos processos de acumulação e distribuição da riqueza e do poder e, nesse contexto, os recursos intelectuais se tornaram fatores estratégicos para o desenvolvimento da competitividade econômica dos países. Assim também apontam Di Pierro e Haddad (2000), para quem a educação continuada se tornou um eixo estrutural dos modelos de desenvolvimento nacionais nas últimas décadas. Segundo os pesquisadores, 
A extrema valorização da educação nas sociedades pós-industriais está relacionada à aceleração da velocidade de produção de novos conhecimentos e difusão de informações, que tornaram a formação continuada um valor fundamental para a vida dos indivíduos e um requisito para o desenvolvimento dos países perante sistemas econômicos globalizados e competitivos. $O$ paradigma de educação continuada emergente nessas regiões concebe como espaços educativos múltiplas dimensões da vida social, inclusive os ambientes urbano e de trabalho, as associações civis, os meios de comunicação e as demais instituições e aparelhos

culturais. Nesse marco, as instituições escolares respondem por apenas uma parcela da formação permanente dos indivíduos, que se apropriam de conhecimentos veiculados por outros sistemas de informação e difusão cultural (DI PIERRO, HADDAD, 2000, p. 127).

Di Pierro (1998) indica também que o acirramento global da competitividade econômica favoreceu diversas mudanças nos processos produtivos e nas relações de produção nas últimas décadas, levando a progressivas mudanças na organização do trabalho. Essa tendência tem sido amplificada por inovações tecnológicas e, na prática, tem exigido, ao menos no plano discursivo de empregadores e de governos, níveis crescentes de qualificação profissional de trabalhadores das mais diferentes hierarquias e funções.

No caso do Brasil nos dias atuais, Schwartzman e Castro (2013) enxergaram um equilíbrio entre os resultados do sistema escolar e as demandas do mercado de trabalho, fruto do aumento da escolaridade da população brasileira nas últimas décadas. Segundo os autores, a economia brasileira não necessariamente demandou, de modo generalizado, maiores qualificações; na visão deles, há um equilíbrio entre qualificação do trabalhador e as demandas do mercado de trabalho.

As análises das características e evolução recente do mercado de trabalho brasileiro não confirmam a ideia generalizada de que o país está vivendo um grande "apagão" de mão de obra qualificada, o que tornaria urgente a necessidade de investir pesadamente na formação técnica de nivel médio ou superior. Existe demanda reprimida por pessoal qualificado em determinados setores, tanto de nivel médio quanto de nivel superior, mas estes setores empregam, relativamente, poucas pessoas. Em termos gerais, parece existir um equilíbrio entre as qualificações proporcionadas pelo sistema educativo e as necessidades mais gerais do mercado de trabalho, e o aumento da qualificação média dos trabalhadores que se observa se deve mais ao aumento geral da escolaridade da população brasileira do que a um aumento generalizado de demanda por maiores qualificações (SCHWARTZMAN; CASTRO,

2013, p. 609).

Mesmo que as análises de Schwartzman e Castro (2013) mostrem algumas nuances na relação entre educação e trabalho (no caso, mais especificamente, emprego), reforçou-se, nos últimos anos no Brasil, a tendência de incentivo ao aperfeiçoamento constante de trabalhadores como uma estratégia de 
empregabilidade e, sobretudo, de fomentar a melhoria de processos de trabalho na busca por maiores níveis de eficiência e, logo, de competitividade econômica. Nesse contexto, empresas de diferentes setores da economia brasileira, assentadas também em análises economicistas sobre 0 descompasso entre formação escolar e competências profissionais exigidas na economia atual, têm apostado no incremento dos investimentos em processos formativos próprios, internos aos ambientes de trabalho, voltados ao treinamento e à capacitação para desenvolvimento profissional.

Nesse contexto, a experiência aqui descrita e problematizada procurou criar uma metodologia educacional que não se resumisse unicamente ao aperfeiçoamento profissional, mas que propiciasse percursos formativos básicos voltados a um maior domínio, por parte de trabalhadores desse segmento profissional, de práticas linguísticas, textuais, discursivas e relativas à matemática vinculadas a demandas de letramento e de numeramento próprias do contexto de trabalho, prioritariamente, além de outras presentes em suas atividades cotidianas. Não se trata apenas de promover o aprendizado de uma técnica de trabalho, mas de desenvolver formas de usar leitura, escrita e matemática para transitar, interagir e construir sentidos no mundo social e em contextos específicos de trabalho.

Os trabalhos de criação da metodologia tomaram como ponto de partida dados de experiência detalhada em artigo de Catelli Jr., Novis e Serrao (2015). Os autores apresentam o processo de criação de um INDICADOR DE ALFABETISMO ${ }^{1}$ junto a trabalhadores da indústria petroquímica em Camaçari (BA). 0 instrumento em questão estava focado em mapear níveis de alfabetismo dessa população, com base em pressupostos teórico-metodológicos desenvolvidos para o Indicador de Alfabetismo Funcional (Inaf) ${ }^{2}$. No ano

Concebemos indicador de alfabetismo como um processo avaliativo composto de um conjunto de pressupostos teórico-metodológicos acerca do alfabetismo, uma matriz de avaliação organizada segundo critérios específicos; descritores derivados dessa matriz e desses pressupostos e que indicam as habilidades a serem avaliadas; além dos itens de avaliação, que podem ser questões abertas e fechadas, relacionadas aos descritores (Cf. AÇÃO EDUCATIVA; SESI, 2014b).

O Inaf é uma pesquisa realizada pela Ação Educativa em parceria com o Instituto Paulo Montenegro e Ibope, que mensura o nível de alfabetismo da população brasileira entre 15 e 64 anos, avaliando suas habilidades e práticas de leitura, de escrita e de realização de operações matemáticas aplicadas ao cotidiano. 0 Inaf trabalha com uma escala de proficiência dividida em quatro níveis de alfabetismo: analfabeto, rudimentar, básico e pleno. Disponivel em: 〈http://www.acaoeducativa.org/index.php/component/content/ article/54-institucional/76-indicador-nacional-de-alfabetismo-funcionalı. Acesso em: 30 out. 2015. 
de 2011, 711 trabalhadores realizaram as atividades propostas e, naquele momento, descobriu-se que:

- 35,4\% dos avaliados situaram-se no nível 1 da escala, ou seja, demonstraram capacidade de interpretar imagens, frases curtas, textos breves acompanhados ou não de imagens, localizando informações explícitas sobre situações e/ou temas do cotidiano (Ex.: segurança no trabalho).

- $62,3 \%$ dos respondentes situaram-se no nível 2, ou seja, mostraram capacidade de interpretar imagens, textos de extensão mediana, com vocabulário mais complexo, quadros, tabelas e gráficos, realizando inferências simples com base em conhecimentos prévios, remetendo a diferentes partes do texto; de estabelecer relações temporais e causais; de realizar cálculos em algumas etapas incluindo as quatro operações matemáticas, porcentagem e probabilidade, de avaliar e tomar posição sobre uma determinada situação-problema.

- apenas 2,4\% ficaram no nível 3, ou seja, demonstraram capacidade de interpretar imagens, textos de extensão mediana, com termos técnicos, quadros, tabelas e gráficos, realizando inferências com base em dados diversos; de comparar dados de dois textos, estabelecer relações temporais e causais; de compreender efeitos de sentido (metáfora, ironia, hipérbole, etc.); de indicar decisões a ser tomadas com base na interpretação dos textos; de realizar cálculos complexos envolvendo as quatro operações matemáticas e etapas diversas; de estimar resultados a partir de tendências; de comparar informações/ resultados de fontes diferentes sobre um mesmo tema; e de formular respostas mais complexas.

Os resultados indicam que os sujeitos cursistas tinham grandes dificuldades quanto à leitura e à escrita, uma vez que poucos demonstram domínio da leitura, da escrita e dos números compatível com o nível 3.

Desenvolvida no contexto de alargamento das fronteiras educacionais para diferentes espaços e ambientes, inclusive no mundo do trabalho, indo além das já tradicionais propostas escolares, a metodologia foi elaborada a partir da demanda de uma instituição voltada ao atendimento educacional dos trabalhadores da indústria petroquímica baiana. Como resultado dessa elaboração, obtiveram-se: uma proposta teórico-metodológica; materiais didáticos específicos; além de estratégias de formação, acompanhamento e avaliação específicos. 


\section{PRESSUPOSTOS TEÓRICO-METOdOLÓGICOS}

Para desenvolvê-la, partiu-se de pelo menos dois pressupostos principais, os quais se apresentam interligados. Entende-se, em primeiro lugar, que todo trabalho - da concepção da metodologia às propostas de atividades do curso - esteve imbuído e coerente com a perspectiva de educação continuada ao longo da vida, ou seja, um processo de aprendizagem no qual as pessoas envolvidas possam valorizar e desenvolver saberes, culturas e qualificações profissionais, de modo a satisfazer suas necessidades e desejos individuais ou coletivos.

Essa perspectiva ainda se alinha com a ideia de que, como aponta Nouroudine (2002), o uso da linguagem no contexto profissional cotidiano assume um papel de destaque em diversas situações; nesse âmbito, fala-se/escreve-se/ visualiza-se para si e para o outro, uma vez que a realização do trabalho, as identidades profissionais pessoais e de grupo encontram-se baseadas nas práticas discursivas e sociais com os mais diversos textos - o que é concebido aqui como atividades e práticas de letramento e de numeramento.

É relevante pontuar que tais práticas - assim como os textos, os gêneros e os suportes - modificam-se ao longo do tempo e das comunidades de práticas. Se a escrita surge como uma necessidade dos seres humanos de expressão e de interlocução, cumprindo finalidades nelas imbricadas de armazenamento e registro de informações a fim de comunicá-las, a si mesmos ou a outros, distantes no tempo e no espaço, pode-se dizer que ela foi assumindo diferentes formas, estilos e funções sociais ao longo dos séculos. De forma análoga, sua aprendizagem e seu desenvolvimento modificam-se no decorrer do tempo. Nem sempre se viveu e nem todos vivem em uma sociedade na qual instituições como a escola se responsabilizam por inserir formalmente os sujeitos na cultura escrita. Em muitas situações, outras instituições como a igreja, os ambientes de trabalho, a família, por exemplo, também se organizam em torno de práticas letradas e influenciam os modos como os sujeitos se apropriam da leitura e da escrita, os modos como atribuem (des) valor a essas práticas, etc.

Como as práticas de letramento são diversas, a proposta estabelecida para uma educação linguística crítica que tome o mundo do trabalho como um espaço central ou privilegiado na vida do sujeito, assim como a adotada na metodologia desenvolvida, envolve um trabalho que vai além de uma compreensão abstrata dos sistemas alfabético e numérico. Diferentemente, procura-se partir de atividades que levem os sujeitos a ter consciência de 
como os grupos sociais interagem com a cultura escrita, utilizando os mais diversificados gêneros para as mais complexas atividades em seu cotidiano. Nessa direção, Mendonça (2005, p. 55) defende que "não se pode falar em gêneros sem considerar os processos de letramento; não se pode falar em letramento sem considerar os gêneros", ou seja, um passo importante para a elaboração de projetos educativos que envolvam práticas de letramento específicas é o mapeamento das diversas práticas de letramento e dos gêneros que os adultos já utilizam ou daqueles que podem/devem utilizar para (sobre)viver nas cidades contemporâneas em que a cultura escrita exerce uma função essencial no âmbito do lazer, do trabalho, da religião, da escola, das práticas cidadãs, etc.

Diante de tudo isso, entende-se que exercer a cidadania e suas funções no mundo do trabalho implica ser linguística e matematicamente capaz de interagir em tais contextos, além de implicar também outras competências e habilidades igualmente importantes. Dentro do recorte do presente trabalho, isso não significa apenas conhecer algoritmos matemáticos e estruturas gramaticais, mas envolve necessariamente o domínio de práticas situadas de letramentos e numeramentos, entendidas como aquelas práticas sociais em que a leitura, a escrita e/ou o uso de números servem para mediar interações dos sujeitos com os textos.

Partiu-se do conceito de letramento e numeramento no plural - letramentos e numeramentos -, considerando que sujeitos se engajam em diferentes ações e atividades em que textos escritos e visuais assumem uma função importante. No âmbito dos Novos Estudos do Letramento (New Literacy Studies, NLS), existem "diferentes práticas de letramento associadas a diferentes domínios da vida" (BARTON; HAMILTON, 1998, p. 8). Tais práticas englobariam não só habilidades cognitivas para lidar com textos escritos, seja para ler, seja para escrever, mas também concepções acerca dos conhecimentos, crenças, valores e relações de poder associados a essas práticas. Para Street (1993, 2006), o significado e os usos das práticas de letramento estão relacionados com contextos culturais específicos e tais práticas estão sempre associadas com relações de poder e ideologia. Em outras palavras, saber ler e escrever em qualquer contexto social não é simplesmente tecnologia neutra.

$\mathrm{Na}$ vida familiar, na vizinhança, no bairro, nas práticas religiosas e no comércio, as pessoas e, muito especialmente, os adultos interagem com (leem, ouvem, escrevem, produzem oralmente) uma grande diversidade de gêneros do discurso. Assim, a vida adulta, em uma sociedade letrada como a 
nossa, encontra-se atrelada à interpretação e à produção de textos (escritos, orais, visuais) nas mais diferentes situações. 0 trabalho de leitura e produção textual (oral e escrita, multimodal) nas instâncias educativas mostra-se central para que os sujeitos possam compreender mais amplamente o papel da linguagem nos mais diversos contextos da vida pública e seus diversos usos, além de possibilitar-lhes atuar de forma mais autônoma e crítica por meio da linguagem.

Os usos sociais da leitura e da escrita, por sua vez, estabilizam certos tipos de textos, que são recorrentemente mobilizados nessas situações ${ }^{3}$. Os gêneros textuais/ discursivos constituem parte da proposta, já que nos inserimos nos inúmeros eventos de letramento pelo uso de gêneros orais, escritos e multimodais. 0 manejo dos diferentes tipos de discurso imbricados nesses gêneros exige capacidades específicas e também mobiliza capacidades transversais aos gêneros (SCHNEUWLY, 2004), que podem ser utilizadas para outras finalidades. Nos contextos profissionais, é comum que os sujeitos trabalhadores delas se apropriem ou as ampliem por força das tarefas que desempenham e pelas interações singulares que se estabelecem nesses locais.

Em linha com a discussão até aqui apresentada, assumimos o seguinte pressuposto: os trabalhadores em foco são sujeitos históricos e culturais que estão inseridos em diversas práticas e eventos de letramento. Desse modo, já dominam determinados usos da língua e convivem, diariamente, com a cultura escrita em diferentes práticas sociais. No entanto, sabe-se também que eles, assim como muitos brasileiros, apresentam dificuldades em algumas situações e atividades - em grande parte relacionadas a demandas institucionais (como as do local de trabalho) ou públicas (como questões relacionadas à cidadania e a direitos) - que envolvem compreender, interpretar e analisar as informações verbais e numéricas, produzir textos orais escritos e multimodais. Essas dificuldades surgem justamente quando se exigem certos modos de mobilizar conhecimentos e usos de linguagem relacionados à leitura/compreensão e à produção de textos (orais e escritos).

Para Bakhtin (1997 [1953], p. 280), “O enunciado reflete as condições específicas e as finalidades de cada uma dessas esferas, não só por seu conteúdo (temático) e por seu estilo verbal, ou seja, pela seleção operada nos recursos da língua - recursos lexicais, fraseológicos e gramaticais -, mas também, e sobretudo, por sua construção composicional. Estes três elementos (conteúdo temático, estilo e construção composicional) fundem-se indissoluvelmente no todo do enunciado, e todos eles são marcados pela especificidade de uma esfera de comunicação". 
A seguir, organizamos a exposição segundo itens relevantes para uma visada acerca do referido programa piloto de educação não escolar na indústria petroquímica.

\section{EDUCAÇÃO NO MUNDO ADULTO E MEMÓRIAS SOBRE ESCOLA REGULAR}

Um desafio a uma postura mais experimental ou exploratória em situações de ensino, as quais questionem ou fujam ao padrão da escola regular, consiste justamente em lidar com expectativas e saberes consolidados a respeito do que é ou pode vir a ser escola, ensino, aprendizado, sala de aula, etc. A consideração dos conhecimentos prévios do educando e a própria ideia de uma educação com foco na autonomia do indivíduo em tais casos não deve ser evitada, embora seja uma questão difícil e complexa de ser pensada na prática. Em parte, isso se dá porque, dentre os conhecimentos prévios desse adulto em situação educativa, existe a memória de como se configura (ou deveria se configurar) o espaço de ensino e aprendizagem e os processos que nele ocorrem.

Isto é, ao se evocarem os saberes dos educandos como ponto de partida para um diálogo, ao se colocar como mediador entre esses conhecimentos e alguma outra forma institucionalizada de saber, à qual se atribui a força de uma ferramenta a favor do protagonismo e da autonomia desse sujeito, não se pode ignorar que suas memórias em relação à escola e a um processo mediado de aprendizado - sejam boas ou ruins - e também suas expectativas façam parte desse pacote. Em termos mais específicos, os motivos pelos quais o sujeito está naquele ambiente de aprendizado, as transformações que espera, as aplicações daquele processo para sua vida prática, entre outros, são aspectos a ser compreendidos e levados em consideração em cada processo educativo.

No exemplo específico do curso aqui em análise, pôde-se notar que muitos cursistas, em um momento inicial, não compartilhavam entre si o propósito central da metodologia de curso. Diante disso, trouxeram diferentes expectativas em relação à proposta, ainda que essa tenha sido expressamente apresentada aos sujeitos antes de sua adesão ao curso ${ }^{4}$ e reiterada na abertura do curso. Em linhas gerais, muitos cursistas esperavam cursos de aprofundamento em suas áreas de atuação profissional ou para aprendizados

4 Antes do início da experiência piloto, foi realizada uma palestra sobre os objetivos, a metodologia e a estrutura do curso junto aos trabalhadores, momento no qual estes puderam tirar suas dúvidas e, caso tivessem interesse, se candidatariam a uma vaga. 
técnicos pontuais. Em conversa com uma das formadoras e elaboradoras do material do curso, alguns solicitaram atividades relacionadas a questões específicas do âmbito técnico dos trabalhos executados - que iam de caldeiraria e pintura a montagem de andaimes. Um cursista, em depoimento, mencionou também a quebra de expectativa em relação ao curso. 0 curso, de letramentos e numeramentos no mundo do trabalho, foi interpretado de início pelo cursista como algo voltado apenas a quem não sabia ler ou calcular, ideia da qual se dissuadiu ao longo do tempo.

Nesses casos, o desafio de não reiterar formas hegemônicas de ensino - por vezes cristalizadas pela cultura escolar tradicional ou por experiências em cursos ou treinamentos técnicos de diversas ordens - pode passar pelo ato de debater com o próprio educando pressupostos pedagógicos diferentes, seus limites e possibilidades. Com isso, abre-se mão do conforto em reiterar uma estrutura, uma metodologia e uma proposta educativa que, ainda que nem sempre se mostrem concretamente benéficas, costumam ser mais aceitas enquanto imaginárias do que é "aprender", "educar" ou "ensinar". Um exemplo seria praticar, na Educação de Jovens e Adultos (EJA), aquilo que Freire (1996) denomina “educação bancária”, fundamentada na ideia de transmissão unilateral de conhecimento, ainda que se perceba não ser uma prática adequada ao contexto em questão.

Isso não quer dizer que a sala de aula deva se tornar uma discussão entre especialistas na área da educação. Antes disso, trata-se de analisar esse conflito de expectativas, quando existir, justificando e negociando o caminho educativo proposto. Ou, mais especificamente, apontar a relação entre os objetivos daquela ação educativa e da metodologia utilizada - e sua operacionalização - para concretizar tais metas. Dessa forma, a experiência piloto aqui relatada sofreu diversas modificações e ajustes ao longo de sua implementação a fim de se tornar o mais relevante possível para os sujeitos cursistas e para as finalidades da formação proposta.

\section{INFRAESTRUTURA DO AMBIENTE DE ENSINO DO TRABALHADOR}

Dentro do conjunto de questões que exige atenção a uma proposta educativa voltada a jovens e adultos trabalhadores, algumas vão além das escolhas metodológicas e de conteúdo ou da atuação do professor. É relevante também, por exemplo, refletir previamente a respeito de como viabilizar e escolher local e mobiliário adequado para as atividades pedagógicas. De um ponto de vista prático, um problema comum encontrado em ambientes de 
ensino voltados a jovens e adultos diz respeito às condições de infraestrutura nas quais a prática educativa se realiza. Essa situação não se refere apenas a situações informais de educação, mas acaba ocorrendo também no sistema formal de ensino, conforme apontado em Catelli Jr. et al. (2013), para quem:

Grande parte das escolas para jovens e adultos no Brasil funciona como reprodução simplificada do trabalho realizado na escola tradicional, voltada para crianças e adolescentes. Um retrato dessa incoerência é a frequência com que são vistas salas de aula e bibliotecas com carteiras projetadas para crianças pequenas sendo utilizadas por adultos e salas de aula decoradas com cartazes e dizeres relacionados ao público infantil (CATELLI

JR. et al, 2013, p. 163).

No processo educativo aqui analisado, dificuldades ocorridas em termos de infraestrutura reiteraram essa preocupação. A esse respeito, vale ressaltar que dados de questionários padronizados aplicados em março de 2014, com 24 respondentes, foram majoritariamente positivos em relação a questões de equipamentos e condições de funcionamento disponíveis. 0 ponto menos satisfatório, entre todos, foi justamente o de infraestrutura e espaços, em que $50 \%$ dos sujeitos apontaram a infraestrutura e os espaços como bons ou ótimos, e $46 \%$ como regulares 5 .

Na avaliação sobre a escola que sediou a experiência piloto, a inadequação de mobiliário - indicada na citação acima como característica de uma educação voltada para jovens e adultos subjugada a uma primazia da escola tradicional de público infantojuvenil - foi um dos principais empecilhos apontados pelos trabalhadores envolvidos nesse processo. Tal inadequação decorreu de uma dificuldade em conseguir espaços adequados disponíveis para o período de curso previsto no município de Camaçari (BA). Os poucos espaços que poderiam cumprir as exigências do curso (que, além de mobiliário para adultos incluía, por exemplo, acesso à internet e acesso fácil aos trabalhadores na região de Camaçari), já estavam ocupados para tal período.

Esse ponto pode ser ilustrado a partir de dois depoimentos, realizados em uma roda de conversa com cursistas, após a cerimônia de desfecho da experiência piloto:

E a carteira que tinha lá, não era própria para notebook. A carteira que tinha no colégio era uma carteira para criança de 5 anos, tinha até que passar pelo lado. Entendeu? Então para a gente ficava um pouco inadequada a cadeira (AÇÃO EDUCATIVA; SESI, 2014b, p. 36).

\footnotetext{
Para fins de comparação, o resultado dos outros itens investigados foi o seguinte: $100 \%$ consideraram como bons ou ótimos os cadernos dos cursistas; $87 \%$ consideraram como bons ou ótimos os materiais e equipamentos de apoio; $83 \%$ consideraram como bom 0 transporte; $70 \%$ consideraram como bom ou ótimo o apoio da empresa; $54 \%$ disseram que a alimentação fornecida era boa ou ótima, enquanto $46 \%$ apontou-a como regular.
} 
Entende-se que a relevância da importância de aspectos relacionados à infraestrutura e condições de funcionamento de curso expostas pelos depoimentos abarca pelo menos dois pontos: em primeiro lugar, inadequações estruturais podem fragilizar um processo educativo que, no caso do ensino de jovens e adultos com pouca escolaridade, já costuma ser delicado. Além disso, conforme puderam ser percebidos a partir do depoimento de um cursista, tais aspectos podem até mesmo aumentar o índice de evasão de um curso:

Eu ainda acho que, ali, foi um dos itens que mais colaborou com o índice de desistência do curso, foi essa parte da logística. Porque algumas pessoas chegaram até expor a situação. A gente teve dificuldade no horário de saída aqui, era muito curto. A gente teve dificuldade de transporte, aconteceu dia de atraso, o dia de falta de transporte. A gente teve dificuldade com lanches. Tem essa dificuldade que ele falou também da saída, o retorno para casa, que a empresa até colaborou, ela deu a passagem para a pessoa, mas ela, a pessoa se sente assim, você saía de lá... [...] Vai sete e meia, mas você depende de outro transporte, de pegar um transporte e tinha gente que morava em vilas, ai tinha que pegar o transporte para um ponto, determinado ponto; desse ponto, pegar outro para as vilas. Só passava um ônibus, tinha que sair correndo para pegar isso aí [...] (AÇÃO EDUCATIVA; SESI, 2014b, p. 27).

A despeito das questões pontuais apresentadas, outros aspectos - como as condições de ventilação e de limpeza da escola e das salas de aula utilizadas - foram sempre elogiados pelos cursistas. Destacou-se, também, a disposição da equipe responsável pelo espaço em resolver problemas e situações. Assim, em vez de uma infrutífera busca por culpados ou responsáveis pontuais em situações como essas, pode ser mais interessante entendê-las como questões sintomáticas do local estrutural em que sujeitos jovens e adultos em situação de ensino ocupam no cenário educacional brasileiro atual. Chama a atenção, portanto, a oferta insatisfatória de espaços adequados para a demanda em questão, a qual, considerando as tecnologias atuais, não deveria ser vista como extraordinária, especialmente se considerarmos o grande número de empresas situadas no polo petroquímico de Camaçari (BA) - mais de 60, segundo o Cofic ${ }^{6}$. 0 entendimento dessa situação, além disso, deve ser visto de modo propositivo, ou seja, como foco de atenção na elaboração de cursos para públicos similares.

6 Comitê de Fomento Industrial de Camaçari, associação empresarial privada que representa mais de 60 empresas no polo de Camaçari. Disponível em: 〈http://www. coficpolo.com.br/2012/index.php». Acesso em: 28 out. 2015. 
Enfatiza-se a ideia de que as práticas de letramento e numeramento de educandos jovens e adultos devem ser tomadas como base para uma ação educativa. Isso se torna ainda mais relevante quando as práticas de letramento são concebidas como atravessadas por crenças e expectativas dos sujeitos, as quais interferem nos modos como eles irão se inserir nos processos educativos que demandem ler, escrever e interagir com a mediação de materiais escritos. Há também o desafio de lidar com um público heterogêneo, com saberes não necessariamente coincidentes e expectativas variadas a respeito do que é ou deveria ser estar em uma sala de aula. Essas indicações norteiam grande parte das análises aqui presentes. Deve-se levar em conta ainda o perfil desse adulto e a tendência de sua trajetória de aprendizado em um mundo de letras e números estar marcada por vivências em ambiente de trabalho. Como afirma Oliveira:

O adulto está inserido no mundo do trabalho e das relações interpessoais de um modo diferente daquele da criança e do adolescente. Traz consigo uma história mais longa (e provavelmente mais complexa) de experiências, conhecimentos acumulados e reflexões sobre o mundo externo, sobre si mesmo e sobre as outras pessoas. Com relação à inserção na aprendizagem, essas peculiaridades da etapa da vida em que se encontra o adulto fazem com que ele traga consigo diferentes habilidades e dificuldades (em relação à criança) e, provavelmente, maior capacidade de reflexão sobre o conhecimento e seus próprios processos de aprendizagem

(OLIVEIRA, 2001, p. 18).

Essa influência do mundo do trabalho nos saberes e no comportamento dos educandos ficou bem marcada no artigo de Catelli Jr., Novis e Serrao (2015), que apresenta o processo de criação e os primeiros resultados de um indicador de alfabetismo de trabalhadores da indústria petroquímica de Camaçari (BA) no ano de 2011 - os mesmos que viriam a ser o público da ação educativa aqui em investigação. Os dados dessa primeira experiência - que não só antecede a execução do curso aqui em análise, como também fornece bases para essa operacionalização - mostram que:

[...] todos os itens que tiveram índice de acerto acima de 95\% se referem a situações específicas vividas pelos trabalhadores do setor petroquímico; referem-se à leitura de placas de alerta ou de equipamentos de utilização em serviço (CATELLI JR.; NOVIS; SERRAO, 2015, p. 19).

Desse modo, não se pode ignorar o aprendizado próprio e constante de um público adulto, imerso no mundo do trabalho, dentro do qual mantém uma rotina diária na qual há a necessidade de lidar com contingências, tomar decisões e - até mesmo por sobrevivência pessoal, na qual se manter empregado é uma necessidade - aprender os mecanismos de funcionamento da empresa e do setor em que se trabalha. Esse aprendizado pode se dar tanto mais informalmente nas demandas do dia a dia quanto ser estimulado 
pelos contratantes do trabalhador. No grupo aqui observado, por exemplo:

\section{[...] foram identificadas várias práticas cotidianas de trabalho que exigiam maior nivel de alfabetismo. Mais do que isso, existiam diversos periodos de treinamento e também de aprendizagem dentro do processo de trabalho. Quando, por exemplo, algum problema ocorria ou não fosse resolvido automaticamente ao longo dos trabalhos, era uma prática comum os trabalhadores reunirem-se para discutir e analisar cada etapa e decisão tomada fazendo uso de conhecimentos técnico-científicos, leitura e análise de dados para resolver tal problema (CATELLI JR.; NOVIS; SERRAO, 2015, p. 25).}

Essa proximidade entre a rotina de trabalho e as demandas de uma sociedade letrada, seria, assim, um elemento determinante no perfil desses sujeitos quanto a seus conhecimentos e usos da tecnologia das letras. Deve-se considerar, ainda, que essa proximidade foi detectada como mais significativa do que a escolaridade declarada de cada trabalhador:

Assim, na avaliação realizada, puderam ser reunidos indícios de que os níveis de alfabetismo dos trabalhadores eram mais influenciados pelas aprendizagens desenvolvidas e em desenvolvimento no próprio ambiente de trabalho do que pela escolaridade declarada. Os processos de trabalho realizados parecem ter preenchido lacunas criadas ao longo das trajetórias escolares convencionais desses trabalhadores (CATELLI JR.; NOVIS; SERRAO, 2015, p. 25).

Essa relação estreita entre o mundo do trabalho e práticas de letramento e numeramento foi reiterada diversas vezes no desenrolar da experiência piloto, cuja metodologia e operacionalização decorreram dessa avaliação brevemente mencionada. Essas manifestações se deram das mais diversas maneiras. Em certos casos, algum trabalhador apresentava uma solução para um problema ou atividade de modo alternativo ao previsto pelo material didático ou pelo formador. Essa solução viria de sua própria vivência e prática com as demandas envolvidas na atividade. Um exemplo foi uma atividade de geometria, em que certos cálculos de área, previstos como difíceis pelos desenvolvedores do material, foram resolvidos sem maiores problemas por trabalhadores que passavam por desafios semelhantes em sua rotina de trabalho.

A ênfase no mundo do trabalho também auxiliou a despertar novos interesses ou mesmo a transformar a percepção do trabalhador quanto àquele ambiente no qual ele está diariamente presente. Em relação a isso, vale mencionar uma atividade que, a partir de um mapa de risco $^{7}$ da própria empresa material afixado na entrada principal do complexo em que trabalhavam -,

Um mapa de risco é uma maneira de representar graficamente elementos e fatores no espaço físico do local de trabalho que podem gerar acidentes ou doenças ao trabalhador. 
foram abordadas questões de letramento e numeramento. Após a realização da atividade, alguns trabalhadores comentaram que havia ocorrido uma mudança na relação que tinham com tal material. Se antes não entendiam ou sequer fitavam aquele quadro com círculos de diferentes cores e tamanhos, agora passavam na entrada da empresa olhando e compreendendo o que estava sendo detalhado ali a respeito de segurança e prevenção de acidentes de trabalho.

Os poucos exemplos aqui apresentados mostram, portanto, indícios dessa relação entre o mundo do trabalho dos sujeitos envolvidos no curso em questão com suas práticas de letramento e numeramento, reiterando a percepção que resultou da avaliação aplicada em 2011 sobre esse mesmo público. Mais que isso, ajudam a enfatizar essa característica, tão cara a contextos educacionais de jovens e adultos, que é o respeito aos saberes e às demandas próprios da trajetória e da inserção social desse público.

Na próxima seção, essa questão se desdobrará em uma discussão a respeito do perfil heterogêneo de sujeitos adultos em situação de aprendizado, refletindo sobre maneiras educacionalmente frutíferas de se lidar com a ação educativa em tais contextos.

\section{HeterogeneidAdE CONSTITUTIVA dos SUJEITOS}

Na experiência piloto realizada, ficou evidente o perfil heterogêneo do público ao qual o material era destinado. Tal heterogeneidade, comum a situações de ensino, adquire relevância central no presente caso pelo menos por dois motivos. Trata-se, em primeiro lugar, de um público adulto, com conhecimentos prévios e aprendizados extraescolares díspares, havendo também diferenças geracionais. Além disso, o fato de a proposta do curso ser embasada nos conceitos de letramento e numeramento trouxe, como consequência, foco nas práticas locais, situadas, de seu público como ponto de partida. Em outras palavras, é uma proposta que, metodologicamente, inclui os saberes dos envolvidos como parte da prática educativa.

Não se pode ignorar o caráter desafiador que a execução de um curso a partir de uma perspectiva como essa possui. Questões levantadas no processo foram desde organização e nivelamento de turmas, passando por modos de assegurar um aprendizado que, fiel ao foco em letramentos e numeramentos, pudesse, ainda assim, ser mensurado com a aplicação de avaliações de entrada e saída elaboradas - as quais consistem em uma série de questões de múltipla 
escolha focadas em habilidades e competências de letramento e numeramento previamente descritas em uma matriz de referência (cf. AÇÃO EDUCATIVA; SESI, 2014a). Em contrapartida, é de se ressaltar que a heterogeneidade da turma não foi vista como um problema para os trabalhadores; ao menos foi o que pôde ser observado em conversa final entre a equipe de formadores e dois grupos de 15 participantes que concluíram o curso.

Na ocasião, afirmaram que uma atividade considerada desafiadora para um trabalhador nem sempre será para outro - comentário que foi suportado pelos colegas. Isso foi vinculado à especificidade da experiência profissional imediata de cada, o que foge do escopo de uma divisão de complexidade por níveis abstratos ou mesmo de uma progressão linear das tarefas propostas, tal como é observado nas progressões curriculares da escola regular. Ou seja, as vivências de cada um favoreciam o domínio de certas práticas de letramento e numeramento e não de outras. Mais que isso, conforme se notou no decorrer da experiência piloto, o mesmo trabalhador, por vezes, poderia responder bem a atividades do material didático previstas como mais complexas e ter mais dificuldade naquilo que foi imaginado originalmente como mais fácil no momento de formulação do material. Perguntados se eles veriam um modo de lidar com situações similares, apontaram que, na própria condução do curso, lidaram com essas diferenças positivamente, com o formador instigando o auxílio dos mais experientes (em cada assunto ou atividade) para aqueles que tivessem maior dificuldade.

O impasse que emergiu dessa situação consistia em como produzir uma metodologia e um material didático que respondessem positivamente a essa heterogeneidade - de um lado, sem ignorá-la ou suprimi-la, de outro, sem fazer com que isso inviabilizasse o trabalho de formação. A solução proposta para o caso foi a de não segmentar turmas ou cadernos didáticos a partir de níveis estanques, tal como são as séries de uma escola regular. Optou-se, em vez disso, pela criação de um material único, dentro do qual há atividades com (três) diferentes níveis de desafio/dificuldade. Isso em conjunto com um perfil de material que priorizasse certa autonomia do formador em lidar com as particularidades de sua turma, na qual a heterogeneidade é tomada como dado.

Essa gradação organiza as atividades de modo a respeitar a dinamicidade das turmas e de seus participantes. Assim, um trabalhador pode fazer uma atividade de produção textual no primeiro nível de dificuldade e, em seguida, realizar uma atividade de cálculo no terceiro nível, caso seja um conhecimento 
com o qual ele tenha mais familiaridade. Em termos de projeto gráfico, os níveis de desafio foram diferenciados por padrão de cores ("desafio 1": alaranjado; "desafio 2": roxo; “desafio 3": verde). Veja-se o exemplo de uma atividade a seguir, com três níveis de desafio. A atividade se baseou na leitura de um relato de vida acerca do trabalho em açougues.
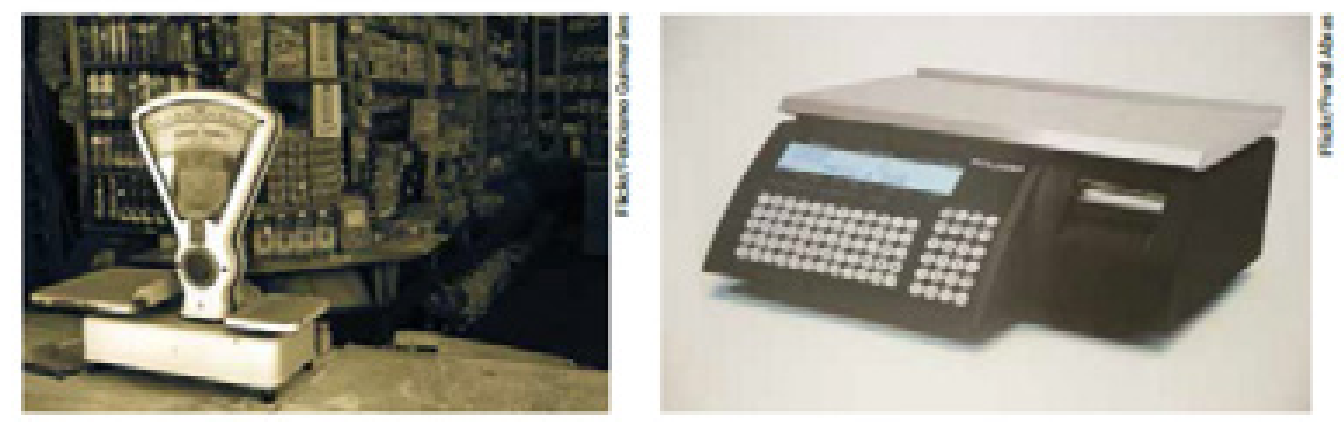

Por que o autor do texto afirma que, atualmente.

Dificuldade 1 os açougueiros não saberiam trabalhar com as balanças antigas?

Por que os trechos a seguir aparecem entre aspas?

Dificuldade 2 "Seu João, tanto de alcatra, tanto disso, tanto daquilo?" E ele dizia: "Dá tanto".

Leia o trecho e responda: Para você, o que essa Dificuldade 3 frase quer dizer? Como chegou a essa conclusào?

A maioria dos açougueiros de antigamente era semianalfabeto, mas tinham muita cabeça.

Figura 1 - Exemplo de atividade proposta com três diferentes níveis de dificuldade. Fonte: Ação Educativa e Sesi (2014c) p. 15.

Entende-se que a proposta em questão trouxe como vantagem maior flexibilidade para as particularidades de cada turma, permitindo harmonizar melhor a multiplicidade interna dos sujeitos. Deve-se reiterar, no entanto, que a solução foi pensada de modo contingente, considerando a especificidade do grupo de educandos envolvidos e a proposta voltada à discussão sobre letramentos e numeramentos no meio do trabalho. Assim, as soluções encontradas não devem ser tomadas como regra para diferentes situações de educação envolvendo jovens e adultos, embora possuam potencial para 
inspirar situações similares. Mais que isso, mostram a possibilidade de uma iniciativa exequível que priorize a heterogeneidade dos educandos.

Outro elemento que deve ser considerado também na metodologia é que muitas atividades pressupõem o trabalho em grupo e discussões para a construção de uma solução. Assim, pessoas que possuem diferentes habilidades e níveis podem atuar em momentos e etapas distintas, além de terem a possibilidade de aprender com a própria construção coletiva.

\section{CONSIDERAÇÕES FINAIS}

A experiência aqui retratada traz ao menos duas grandes implicações para se pensar a relação entre educação e trabalho de pessoas jovens e adultas. A primeira delas é a importância de realizar experiências piloto de cursos e metodologias, fugindo de receitas prontas pensadas em abstrato, abrindo, assim, possibilidades de mudanças em diferentes dimensões da proposta de modo a garantir efetivas aprendizagens.

Essa é uma constatação primordial para pensar processos formativos de pessoas jovens e adultas. Envolvidas em situações de trabalho (remunerado ou não), possuem vivências e trajetórias de vida que favoreceram o domínio de práticas de letramento e de numeramento próprias a determinadas realidades e que não necessariamente são práticas intercambiáveis. Tal bagagem proporciona acesso e domínio diferenciado a práticas letradas, próprias de suas inserções no mundo, e favorece a opção por roteiros de trabalho flexíveis e adaptáveis em vez de materiais didáticos tradicionais organizados segundo uma progressão linear de tarefas e atividades. Tal opção mostrou-se uma estratégia válida no processo da experiência educativa aqui brevemente descrita e analisada.

Essa primeira implicação determina, em parte, a segunda: uma metodologia heterodoxa implica desafios. De um lado, é preciso conciliar os objetivos da proposta às expectativas dos sujeitos diretamente envolvidos nos processos de formação. Como citado anteriormente, os motivos pelos quais um determinado sujeito está naquele ambiente de aprendizado, as transformações esperadas e desejadas, as aplicações daquele processo para a sua vida prática, entre outros, são aspectos a ser compreendidos e levados em consideração em cada processo educativo. $E$, de outro, há a necessidade de reforçar processos de formação de educadores, muitas vezes, com sua formação inicial e experiência profissional atreladas a modelos educacionais 
não condizentes com a perspectiva de criação de novas práticas e com a ressignificação de habilidades. Além disso, como se pode ver, infraestrutura, equipamentos e condições de funcionamento estão diretamente ligados à permanência dos sujeitos ao longo de um processo formativo, sobretudo no caso de jovens e adultos trabalhadores.

De maneira geral, a criação de uma metodologia educacional que não se resumisse unicamente ao aperfeiçoamento profissional mostrou-se um importante exercício de reflexão sobre as relações entre educação e trabalho. Contudo, faz-se necessário um acompanhamento longitudinal dos trabalhadores participantes para, de fato, entender se há e quais são os impactos de um processo formativo dessa natureza no desenvolvimento profissional e pessoal desses sujeitos. 


\section{Non-school education in work contexts: indications for education of youth and adults}

Abstract: This article seeks to deepen discussions on uses of language in the workplace to elucidate important aspects in the process of design and implementation of educational proposals for young and adult workers. It presents the main results of a non-school education experience in a petrochemical industry, focusing on the development of literacy and numeracy practices situated in the contexts of personal life and workplace of the subjects involved. Generally speaking, this article shows that both young and adult workers have experiences and personal circumstances which favored mastering literacy and numeracy practices due to certain contexts, and that such practices are not necessarily interchangeable; in other words, we point to need for approximation between education proposals and the daily lives of the individuals they target.

Keywords: Non-school education. Adult education. Literacy. Numeracy. 


\section{REFERÊNCIAS}

AÇÃO EDUCATIVA; SESI. Letramentos e numeramentos no mundo do trabalho metodologia e plano de curso (Circulação interna). São Paulo: Ação Educativa, 2014a.

; _-___-_ Letramentos e numeramentos no mundo do trabalho Relatório final de experiência-piloto (Circulação interna). São Paulo: Ação Educativa, 2014b.

; - Letramentos e numeramentos no mundo do trabalho Módulo I: Caderno do Trabalhador. São Paulo: Ação Educativa, 2014c.

BAKHTIN, Mikhail. Estética da criação verbal. Tradução Maria Emsantina Galvão G. Pereira. 2. ed. São Paulo: Martins Fontes, [1953] 1997.

BARTON, David; HAMILTON, Mary. Literacy practices. In: BARTON, David; HAMILTON, Mary; IVANIC, Roz (Org.). Situated literacies. London: Routledge, 2000. p. 7-15.

CATELLI JR., Roberto; NOVIS, Solange; SERRAO, Luis Felipe Soares. Construção de avaliação de alfabetismo no mundo do trabalho: a experiência do polo petroquímico de Camaçari. In: MASAGAO, Ribeiro; BATISTA, Antonio Augusto Gomes; LIMA, Ana Lúcia Lima (Org.). Alfabetismo e letramento no Brasil: 10 anos do Inaf. Belo Horizonte: Autêntica, 2015.

; ESCOURA, Michele; GONÇALVES, Ednéia; MAGNANI, Luiz Henrique; MATOS, Leonardo Luiz; SERRAO, Luis Felipe Soares. Proposições de organização curricular na educação de jovens e adultos. Cadernos Cenpec, São Paulo, v. 3, n. 2, p. 162-186, jun. 2013.

DI PIERRO, Maria Clara. Tendências emergentes da educação de pessoas adultas na Europa. São Paulo, 1998. 12 p. Mimeografado. ; HADDAD, Sérgio. Escolarização de jovens e adultos. Revista Brasileira de Educação, São Paulo, n. 14, p. 108-130, 2000.

FREIRE, Paulo. Pedagogia da autonomia: saberes necessários à prática educativa. São Paulo: Paz e Terra, 1996.

MENDONÇA, Márcia Rodrigues de Souza. Gêneros: por onde anda o letramento? In: SANTOS, Carmi Ferraz; MENDONÇA, Márcia (Org.). Alfabetização e letramento: conceitos e relações. 1 ed. Belo Horizonte: Autêntica, 2005. v. 1, p. 37-56. 
NOUROUDINE, Abdallah. A linguagem: dispositivo revelador da complexidade do trabalho. In: SOUZA-E-SILVA, Maria Cecília; FAITA, Daniel (Org.). Linguagem e trabalho: construção de objetos de análise no Brasil e na França. São Paulo: Cortez, 2002.

OLIVEIRA, Marta Kohl de. Jovens e adultos como sujeitos de conhecimento e aprendizagem. In: RIBEIRO, V. M. (Org.) Educação de jovens e adultos: novos leitores, novas leituras. Campinas: Mercado de Letras/ABL; São Paulo: Ação Educativa, 2001.

SCHNEUWLY, B. Gêneros e tipos de discurso: considerações psicológicas e ontogenéticas. In: SCHNEUWLY, B.; DOLZ, J. Gêneros orais e escritos na escola. Campinas: Mercado de Letras, 2004. p. 21-39.

SCHWARTZMAN, Simon; CASTRO, Claudio de Moura. Ensino, formação profissional e a questão da mão de obra. Ensaio - Avaliação de Políticas Públicas de Educação, Rio de Janeiro, v. 21, n. 80, p. 563-624, set. 2013.

STREET, Brian. Cross-cultural approaches to literacy. Cambridge: Cambridge University Press, 1993.

. Perspectivas interculturais sobre o letramento. Filologia Linguística Portuguesa, n. 8, p. 465-488, 2006.

Sobre os autores:

Leonardo Luiz de Souza Matos é estudante de Letras na Universidade de São Paulo (USP) e trabalha como estagiário da Ação Educativa.

leonardoluiz_sp@hotmail.com

Luis Felipe Soares Serrao é cientista social pela Universidade de São Paulo e mestre em Educação pela mesma instituição. É assessor da Ação Educativa.

Ifserrao@gmail.com

Luiz Henrique Magnani é licenciado e bacharel em Letras pela Universidade Estadual de Campinas, mestre em Linguística Aplicada pela mesma universidade e doutor em Letras pela Universidade de São Paulo. É professor da Universidade Federal dos Vales do Jequitinhonha e Mucuri.

henriquemagnani@gmail.com 
Márcia Rodrigues de Souza Mendonça é licenciada em Letras pela Universidade Federal de Pernambuco, onde concluiu também o mestrado e o doutorado em Linguística. É professora da Universidade Estadual de Campinas, no Instituto de Estudos da Linguagem, Departamento de Linguística Aplicada.

mendoncamrs@gmail.com

Roberto Catelli Jr. é bacharel e mestre em História pela Universidade de São Paulo e doutorando em Educação pela mesma universidade. É coordenador da Unidade de Educação de Jovens e Adultos na Ação Educativa.

catelli.roberto@gmail.com

Recebido em: junho de 2015

Aprovado em: outubro de 2015 